\title{
CORRECTION \\ Correction to: An Origin of Citations: Darwin's Collaborators and Their Contributions to the Origin of Species
}

\author{
Pedro de Lima Navarro ${ }^{1}$. Cristina de Amorim Machado ${ }^{1}$ (D)
}

Accepted: 25 March 2021 / Published online: 14 June 2021

(c) Springer Nature B.V. 2021

\section{Correction to: Journal of the History of Biology (2020) 53:45-79 https://doi.org/10.1007/s10739-020-09592-8}

The following corrections should be taken into account for above mentioned article:

p. 49 Sentence "[...] which contributes to all the groups of descriptive bibliography $[\ldots]$ " should read "[...] which contributes to all the groups of analytical bibliography $[\ldots] "$.

p. 51 Sentence "Besides the descriptions of the formal citation, Gross, Harmon, and Reidy also discuss [...]" should read "Besides the descriptions of the formal citation, Gross et al. (2002, p. 53) also discuss [...]".

P. 62 The formatting of Graph 1 makes it difficult to distinguish between the two types of bars. A better Graph 1 is published in this Correction.

p. 71 Sentence "[...] Chapters 7 and 15 represent special cases [...]" should read "[...] Chapter 7 represents special cases [...]".

p. 77 Bois-Jourdain's Mélanges historiques, satiriques et anecdotiques (1807) reference is not cited in the paper and should be disregarded.

The original article can be found online at https://doi.org/10.1007/s10739-020-09592-8.

Pedro de Lima Navarro

pedro.navarro97@hotmail.com

Cristina de Amorim Machado

cristina_machado@yahoo.com

1 Maringá State University (UEM), Maringá, PR 87020-900, Brazil 


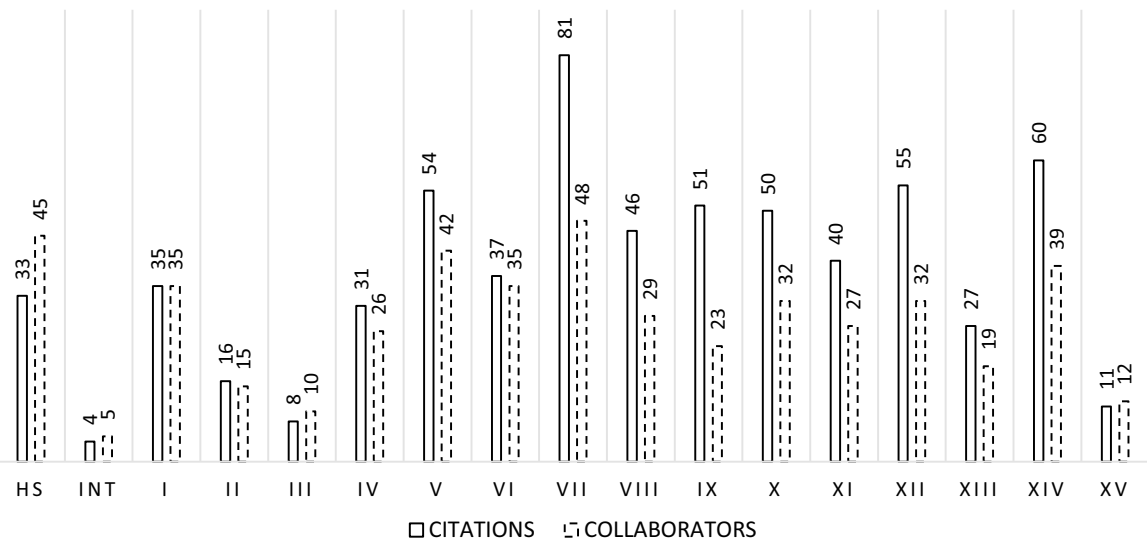

Graph 1 Number of citations and collaborators per section of the Origin of Species

Publisher's Note Springer Nature remains neutral with regard to jurisdictional claims in published maps and institutional affiliations. 